\title{
MODELLING AND SIMULATION OF A CATCHMENT IN ORDER TO EVALUATE WATER RESOURCES
}

\author{
A.L. COURBIS ${ }^{1}$ \\ B. VAYSSADE ${ }^{2, *}$ \\ C. MARTIN ${ }^{3}$ \\ J.F. DIDON-LESCOT ${ }^{3}$
}

\author{
${ }^{1}$ EMA-LGI2P, Parc scientifique G. Besse \\ 30035 Nîmes Cedex 1, France \\ ${ }^{2}$ EMA-CMGD, 6 avenue de Clavières, 30319 \\ Alès Cedex, France \\ 3UMR 6012 "ESPACE" - Département de Géographie \\ 98 Boulevard Edouard Herriot BP 3209, 06204 Nice \\ Cedex 3, France
}

Received: $21 / 12 / 07$

Accepted: 18/03/08 *to whom all correspondence should be addressed: e-mail: bernard.vayssade@ema.fr

\begin{abstract}
It is difficult for decision-makers to evaluate the impact of their territorial policies. Aspects to be considered in this evaluation include those relating to humans, environment protection and industry development. Two reasons explain the difficulty: decision-makers cannot specialise in all domains implied in the process of decision and there is no simple tool allowing questions such as "what would happen if..." to be easily answered.

Our work addresses this problem in the domain of water management at a catchment scale and consists in evaluating water balances. We have developed a software framework allowing simulation scenarios to be easily run and results about outlet flow and groundwater variation to be easily interpreted. In this paper, we study anthropogenic scenarios consisting in modifying the land cover at different scales: parcel, slopes or catchment. The simulation is supported by a methodology allowing catchment models to be built up using a hierarchical and modular approach based on components formalised by sequential machines. Few modelling parameters are necessary because our purpose is not to build up a "perfect" model to represent a catchment from a hydrological point of view but to illustrate the impact of climatic changes or anthropogenic activities on water balance. The simulation interface allows climatic data files to be selected to compare various scenarios. It allows the land-use to be easily modified to understand the impact of anthropogenic activities on water from a quantitative point of view. Modelling and results of simulation are illustrated on a catchment located in the area of Cévennes (South of France).
\end{abstract}

KEYWORDS: hydrologic modelling, water balance evaluation, hydrologic simulation of catchments, discrete event simulation applied to water balance.

\section{INTRODUCTION}

Climatic changes and anthropogenic activities have a long-term effect on our environment, specifically on water resources from both quantitative and qualitative points of view. It is difficult to forecast climatic changes and much more difficult to have any influence on them. However, impacts of human activities can easily be observed and must be controlled, but, decisions about our environment and water policy are not taken with rational criteria. Is there a gap between scientists and decision-makers? Or maybe, the explanation is two-fold: existing tools are too complex to be used because they are based on continuous models the parameters of which are difficult to be precisely adjusted; existing models are not relevant to predict long-term evolution of catchment water balance according to anthropogenic criteria. 
For these reasons, we have been interested in developing a simulation tool for evaluating catchment water balance taking into account climatic and anthropogenic scenarios. Many works have been developed in this area, especially with climatic scenarios but most of them are too complex, with many parameters that cannot be easily evaluated for reasons of cost, time or difficulties explained by the geomorphologic features of the area under study. Furthermore, in many works, the catchment is considered as a unit or as a grid, the cells of which are uniform and of small granularity level, which is time consuming for water balance evaluation and not appropriate for long-term analyses. Our goal is therefore to avoid these drawbacks and to develop a decision-support tool for long-term analysis of catchment water balance. Our approach consists in dividing up the catchment into plots (called parcels) at a suitable granularity level for the spatial variables as well as for time, which is unusual in the domain of hydrogeology. All phenomena interacting in water balance process are independently modelled by discrete event sequential machines. The interconnections of machines are set up in order to highlight relationships of physical phenomena and water transfer from a parcel to other one or several ones. The interconnection defines a graph representing the complete catchment according to a hydrological point of view. This graph is simulated in order to set up the water balance.

To demonstrate our approach, we present in section two the main hydrogeologic phenomena implied in water balance. In section three, we present the methodology of catchment modelling by interconnected finite-state automata. Results obtained on an experimental catchment monitored by CNRS (Centre National de la Recherche Scientifique) experts are presented in section four. We will conclude about the relevance of simulation as a decision support.

\section{WATER BALANCE AT A CATCHMENT SCALE}

A catchment is delimited by a geographical area drained by a river and its tributaries in such a way that all runoff converge to the same outlet. In addition to runoff, basic phenomena involved at a catchment scale are evapotranspiration, infiltration, and those occurring in saturated area: groundwater body recharge and its outflow. Evaluating the water balance of a catchment consists in quantifying exchanges and transfers of these flows over the time (Anctil et al., 2005). We highlight in the two following sub-parts phenomena involved at the soil level and those occurring in the groundwater body.

\subsection{Surface phenomena}

Surface phenomena are evapotranspiration, runoff and infiltration. Evapotranspiration is a combination of evaporation (water movement from wet soil and leaf surfaces to the atmosphere) and transpiration (water movement through plants, also to the atmosphere). This phenomenon mainly depends on climatic conditions: heat issued from the sun radiance on the ground, air and water temperature, air humidity, wind and atmospheric pressure. Other factors are influencing such as water saturation and land cover. Modelling the evapotranspiration is a complex task and for this reason several approaches have been developed (Moges et al., 2003) such as empirical ones (Thornthwaite,Turc) or those issued from energetic analysis (Penman, Penman-Monteith). As we were interested in simulating water balance over two different time scales (monthly and daily), we have implemented Turc formula for month time scale and Penman and Thornthwaite formulae for day time scale.

Water which does not go back to the atmosphere through evapotranspiration either runs off on the surface or infiltrates. Amount of water running at the surface is determined according to a coefficient depending on land cover. The other part fulfils a conceptual tank in the pervious layer till a threshold. The surplus goes to the river through subsurface runoff when the other part reaches the groundwater body. The distribution rate of water between subsurface and groundwater is a parameter adjusted by simulation during the calibration phase of the model.

Let us separate a section of soil, called a parcel, in such a way that the land cover is homogeneous. In addition to surface and subsurface runoff coming out of the parcel, there are same phenomena incoming the parcel from upstream (see Figure 1). At a parcel scale, 
the water balance insures that amount of water incoming a parcel (precipitation upstream surface and subsurface runoff) is equal to subsurface stored water and outgoing flow (downstream surface and subsurface runoff) and infiltration (see equation in Figure 1).

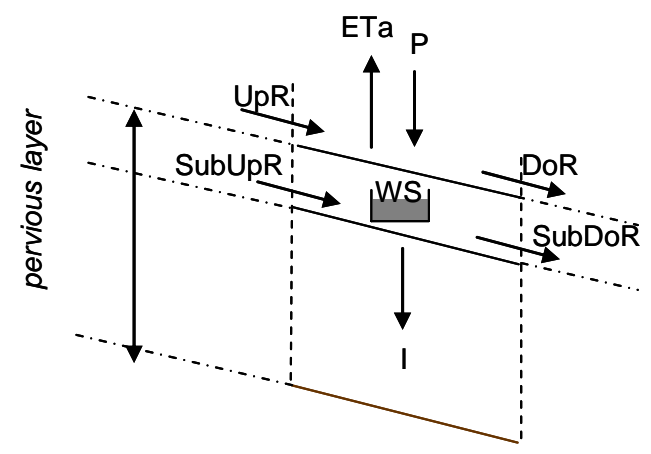

P: precipitation

Eta: actual evapotranspiration

UpR: upstream runoff

DoR: dowstream runoff

WS: water storage

SubUpR: subsurface upstream runoff

SubDoR: subsurface downstream runoff

I: infiltration

Water balance $: P+U p R+S u b U p R=E t a+D o R+S u b D o R+O W S+I$

Figure 1. Hydrological phenomena of the pervious layer and water balance equation

\subsection{Saturated area phenomena}

Infiltration water recharges the groundwater body and consequently increases piezometric levels of the groundwater. Water in the saturated area is flowing to the river according to its natural gradient. The piezometric level of the groundwater body is therefore decreasing and the river outflow is increasing. In this study, we assume that the catchment is located on a homogeneous, non fissured and impervious rock. Consequently, there is no loss in the rock substratum. Darcy's law is a conventional way to compute the groundwater outflow and the piezometric level variation. It is based on the following parameters:

- initial high and low piezometric levels of the groundwater body,

- estimation of its length and width and its permeability.

As previously, if we consider that the surface is decomposed into parcels, each parcel infiltration contributes to the groundwater recharge and the groundwater body can be viewed as a uniform hydrogeologic item the behaviour of which is described by the Darcy's law (see Figure 2).

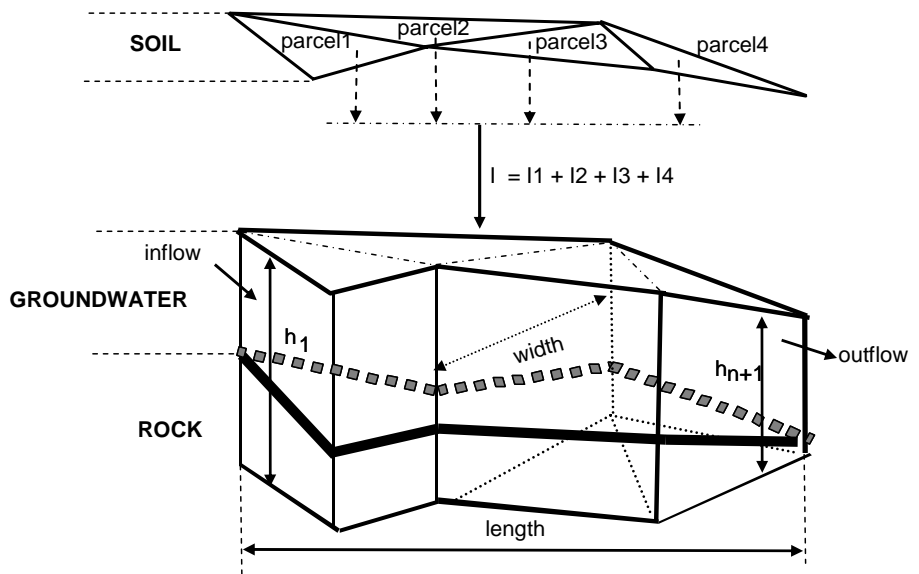

Figure 2. Detailed phenomena involved in the water balance of saturated zone

Having defined which phenomena have to be considered and how they are interacting, we point out how they are modelled and which methodology is applied in order to automatically build up the model of the studied catchment.

\section{HIERARCHICAL AND MODULAR MODELLING OF A CATCHMENT}

We have defined a method to automatically model any catchment (Ordenovic et al., 2002). It consists in decomposing the catchment into three hill-slopes (head of the river, right and left 
sides), each of them leading to recharge a virtual groundwater body and supplying the river with runoff. Every slope is decomposed into parcels in such a way that a parcel is homogeneous from land-use and gradient points of view (see Figure 3).

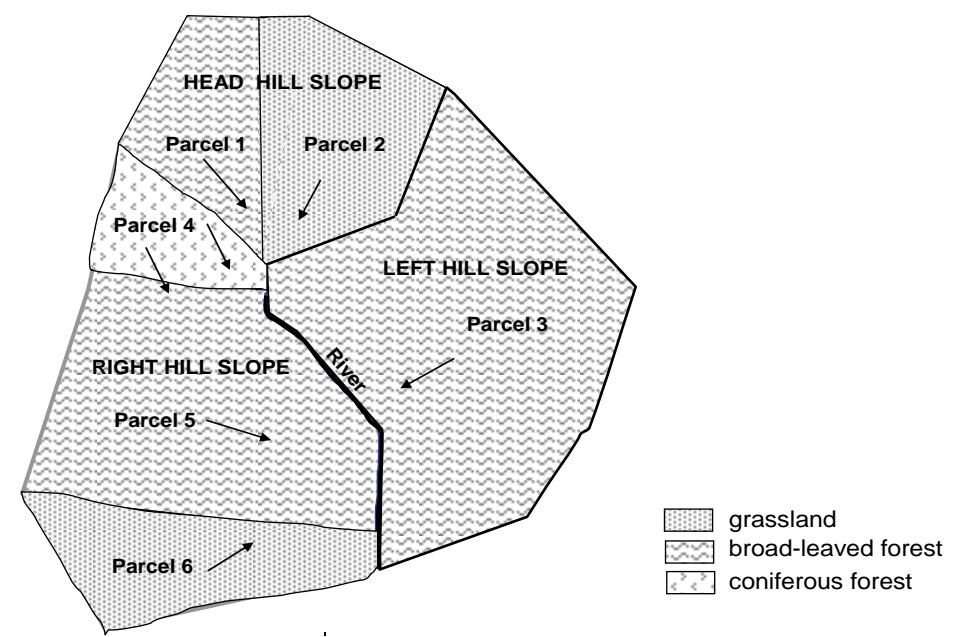

Figure 3. Decomposition of a catchment into slopes and parcels

A parcel is modelled as an interaction of the basic phenomena described in the previous section. In this way, the catchment is modelled by a hierarchical approach consisting in interconnecting models (these models are said structural) by a recursive approach until models can easily describe a phenomenon (these models are said behavioural). The hydrological behaviour of the catchment is deduced from the interaction of its behavioural models.

\subsection{Behavioural modelling of basic phenomena}

Every basic phenomenon described in section 2 is modelled and implemented as a sequential machine, i.e. an automaton characterized by: input/output, internal state and functions to compute both new states and output depending on occurring events. Such an approach has been proposed by Ziegler (1984). Its most interesting feature is to model any behaviour using a unique formalism. All models that will be interconnected for simulation have a common meta-model: by this way, the simulator is independent from the model to be simulated. Furthermore, changing the representation of a phenomenon does not lead to change the simulator: behavioural models are considered as black box that can be changed. Figure 4 gives example of sequential machine developed for modelling the groundwater variation.

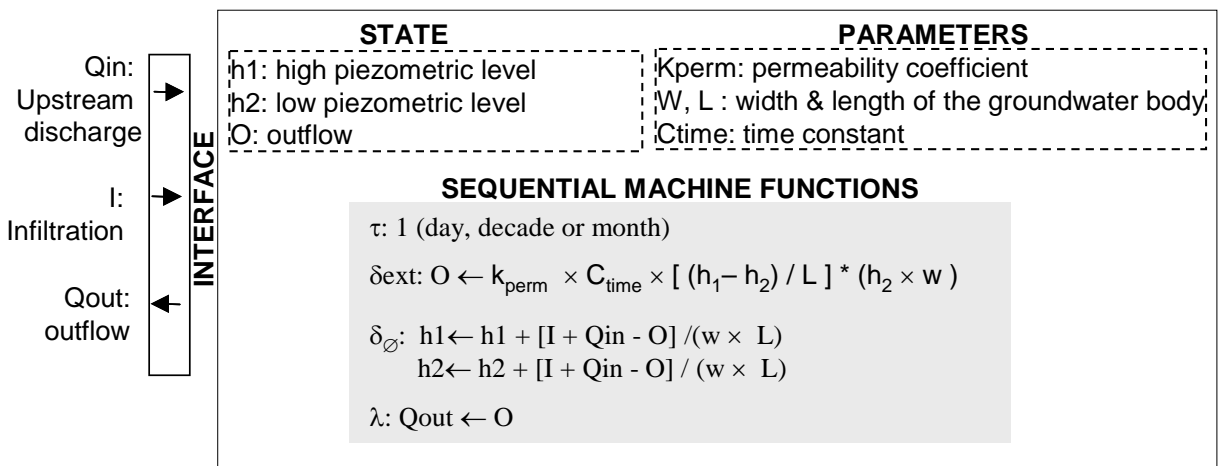

Figure 4. Representation of the groundwater behaviour by a sequential machine

Having defined a taxonomy of models to represent basic behaviours (see figure 5), we have defined rules to interconnect them in order to set up a structural model representing the catchment to be simulated. 


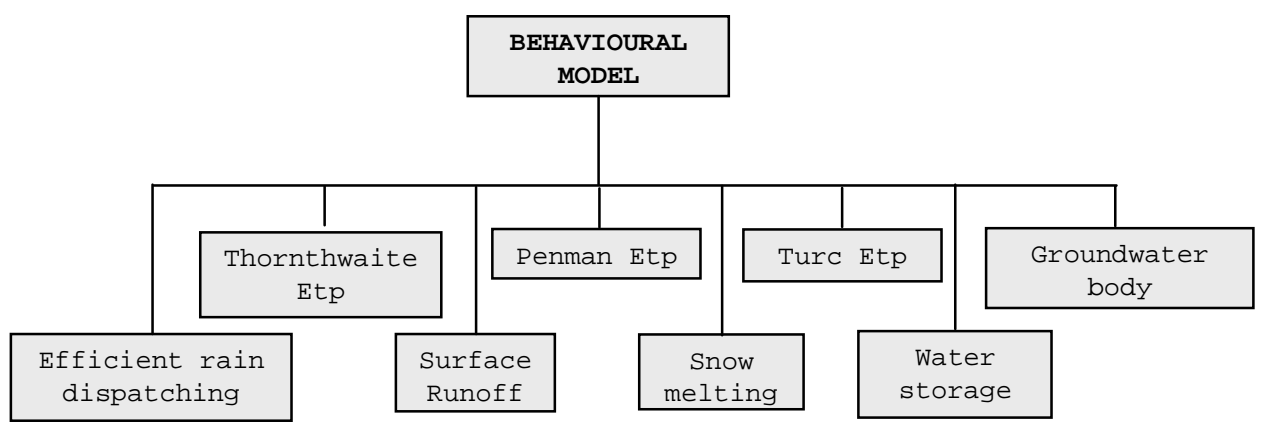

Figure 5. Behavioural classes developed to model water balance phenomena

\subsection{Structural modelling of catchments}

At a parcel level, rules to interconnect models are defined according to water flow in order to represent the relationships between phenomena (cf. figure 6). Rules to interconnect parcel models are defined depending on the topology of the catchment slopes. An example is given in figure 7 representing a slope constituted with two parcels. Slopes run off and groundwater flow are then linked to the river model in order to collect all flows constituting the river outflow.

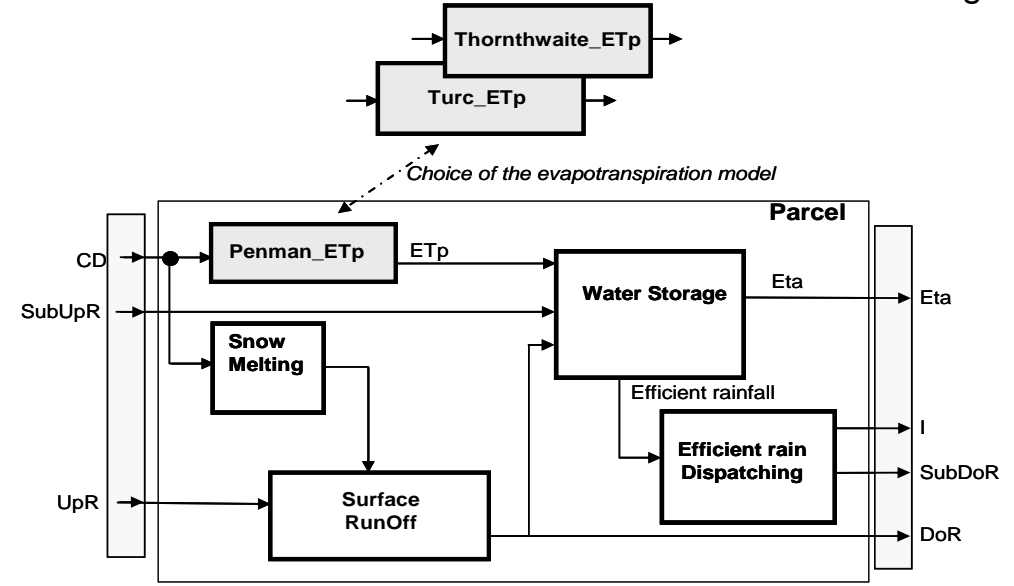

Figure 6. Interconnection of sequential machines at a parcel level

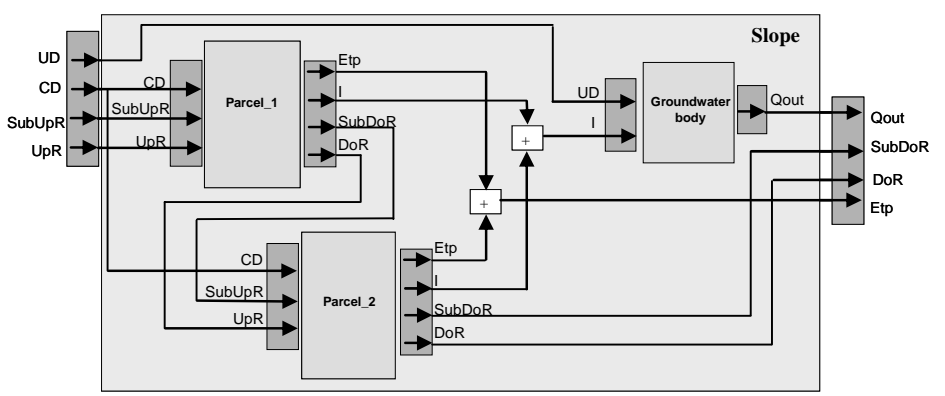

$C D$ : climatic data :

precipitation, temperature, insolation,

moisture, wind speed

SubUpR: subsurface upstream runoff

UpR: upstream runoff

Etp: evapotranspiration

I: infiltration

SubDoR: subsurface downstream runoff

DoR: dowstream runoff

Ud : upstream discharge

Qout :river outflow

Figure 7. Interconnection of behavioural models to represent a slope

The modelling tool has been developed in $\mathrm{C}++$. The model to be simulated is automatically built up by instantiating generic classes modelling behaviours and interconnection rules taking into account data stored in the studied catchment data base. This data base can be set up from a GIS (geographical information system) or from any data base application. The choice of time scale and evapotranspiration model is made by the user.

\section{RESULTS}

\subsection{Description of the studied catchment}

The reference catchment is located on Mont-Lozère and is named La Sapine. It is located on a granite mountain area between the altitudes $1395 \mathrm{~m}$ at the summit of the catchment area 
and $1165 \mathrm{~m}$ at the recording gauge station. The area of the catchment is about 54 hectares. Most of the zone is covered with beeches, the age of which being comprised between 60 years and 1 year. No activity has been developed in this area which belongs to the National Park of the Cévennes. According to experts of the area, the rock is granite and the depth of the soil varies between $0.30 \mathrm{~m}$ and $0.50 \mathrm{~m}$.

The model of the catchment is composed with three hillslopes and six parcels. Three bodies fed by infiltrations coming from parcels belonging to the three hillslopes represent the groundwater. The implementation of the model is based on 44 instantiations of sequential automata and 130 connections.

The catchment outlet flow has been measured by CNRS experts (Martin, 2002) during the last twenty years. Daily measurements are available for this time period as well as climatic data. Piezometric levels of the groundwater are not precisely known.

\subsection{Simulation of climatic scenarios}

\subsubsection{Calibration}

The years 1994 and 1995 have been used for calibration of the model and the years 1996, 97, 98 for the analysis. The evapotranspiration model selected for this study is the Thornthwaite one. In the studied area, the precipitations are important in September and October, giving important outflow of the brook in autumn. On the other side, precipitations are rare in summer so that the brook outflow is very low from June to September (see lower part of Figure 8).

\section{Comparison of simulated and measured outflow over 1994-1995 $($ Nash $=0.68)$}

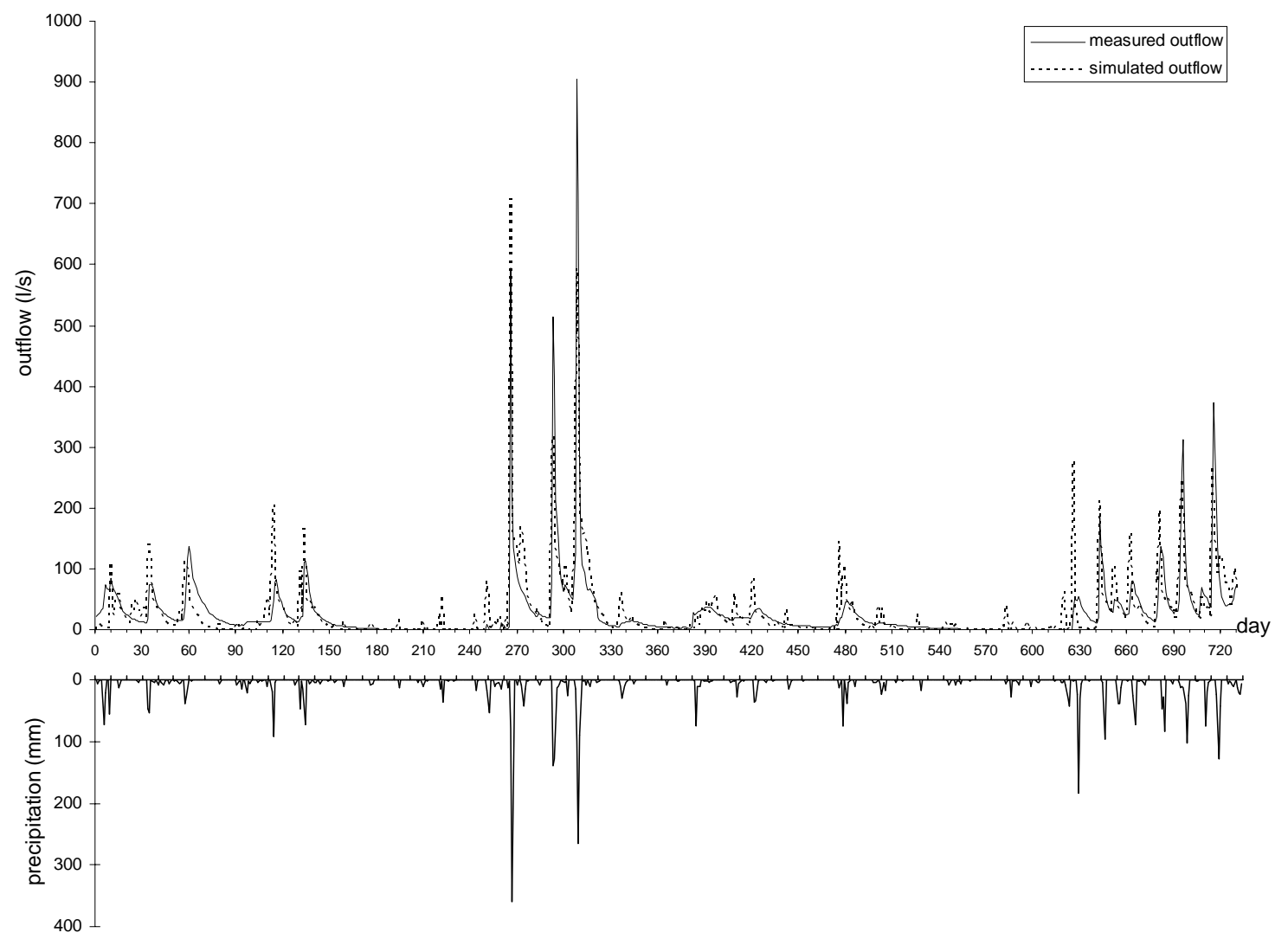

Figure 8. Precipitation and outflow of the river Sapine over 1994-1995

Calibration consisted in looking for the values of different parameters in order to optimise Nash criterion (Nash and Sutcliffe, 1970). This best fit is obtained for the parameter values given in Table 1.The obtained value of this criterion is 0.68 . The simulated outflows obtained for these parameter values are given in the upper part of the figure 8 , compared with the measured ones. 
Table 1. Values of parameters optimising Nash criterion

\begin{tabular}{|c|c|c|c|}
\hline $\begin{array}{c}\text { Available storage } \\
(\mathrm{mm})\end{array}$ & Infiltration rate & $\begin{array}{c}\text { Permeability } \\
\left(\mathrm{m} \mathrm{s}^{-1}\right)\end{array}$ & Nash \\
\hline 400 & 0.20 & $10^{-5}$ & 0.68 \\
\hline
\end{tabular}

\subsubsection{Validation of parameters}

The years 1996, 97 and 98 have been used for the validation of the chosen parameters. Nash criterion obtained for this three year simulation is 0.53 . Values of precipitations and outflows (measured and simulated) are given on the Figure 9.

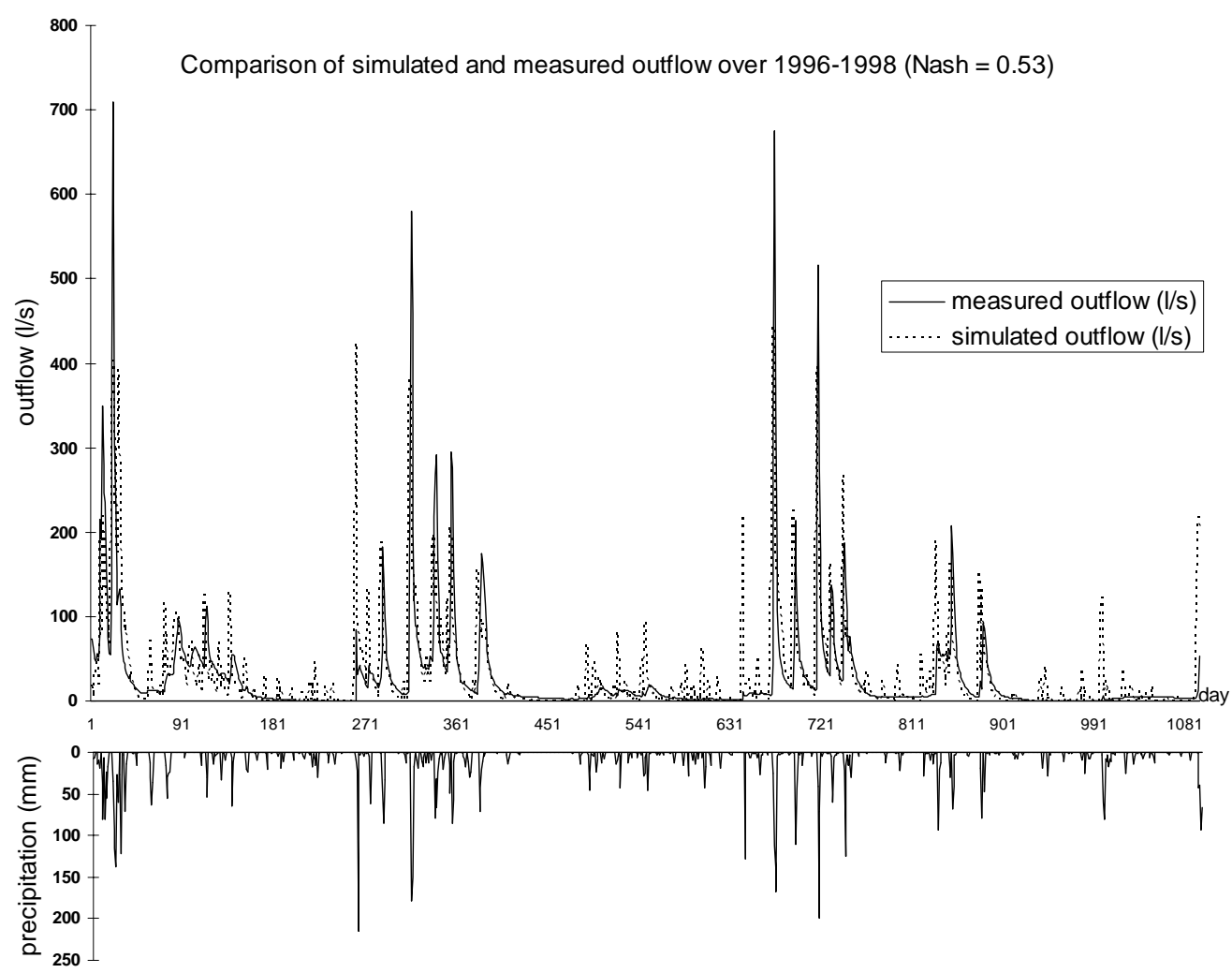

Figure 9. Precipitation and outflow of the river Sapine over 1996-1998

The discrepancy presented in Figure 10 is the difference between the measured and the simulated values; it is negative when simulated value is greater than the measured one. We can see that the simulation tool systematically overestimates the values of outflow in summer and particularly the flows due to important rains of September and October (day 271, day 540, day 991).

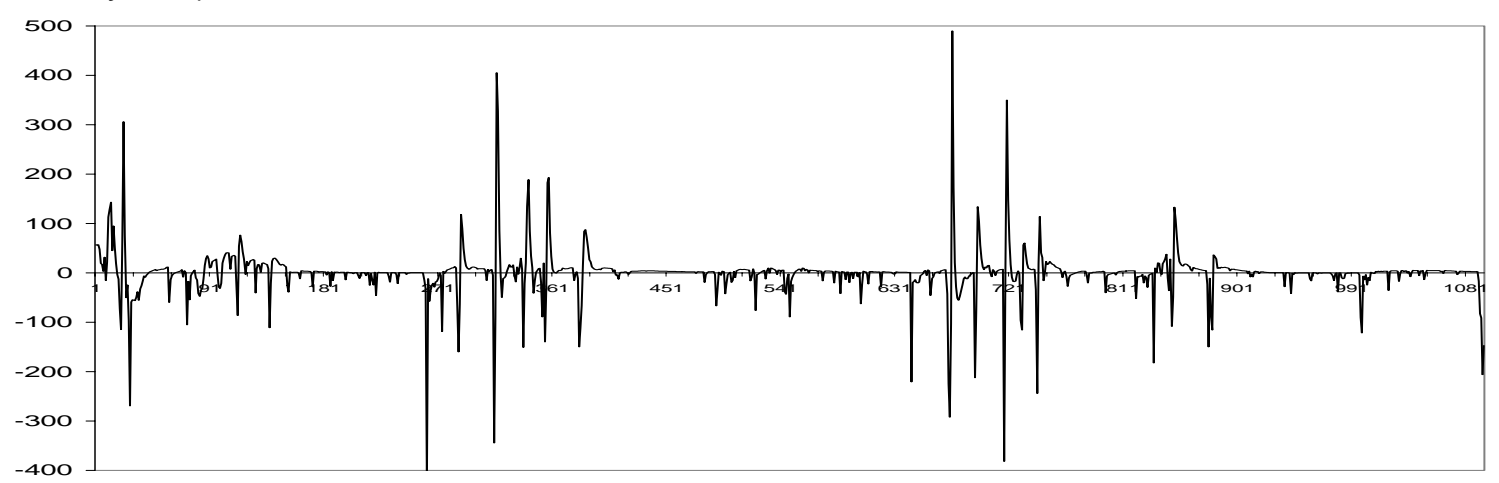

Figure 10. Discrepancy between measured and simulated outflows of the river Sapine over 1996-1998 


\subsection{Analysis of an anthropogenic scenario}

The most common scenario concerning the anthropogenic impact is the change in land-use. To evaluate this impact, a scenario has been defined, consisting in changing the forest into pasture. $72 \%$ of the area of this catchment is covered by trees. The tree-cutting implies the modification of only one parameter (landcover), but the impact concerns the evapotranspiration and run-off coefficients. The simulation has been made with the same meteorological data of the years 1996, 1997 and 1998. Results of the simulation indicate that:

- Mean daily outflow increases slowly: $26, .73 \mathrm{I} \mathrm{s}^{-1}$ after the tree-cutting instead of $26.00 \mathrm{I} \mathrm{s}^{-1}$ previously.

- Outflow at the peak increases frankly: $427 / \mathrm{s}^{-1}$ after the tree-cutting instead of $324 / \mathrm{s}^{-1}$ previously (see Figure 11)

- General evapotranspiration of the whole catchment decreases slightly (Figure 12)

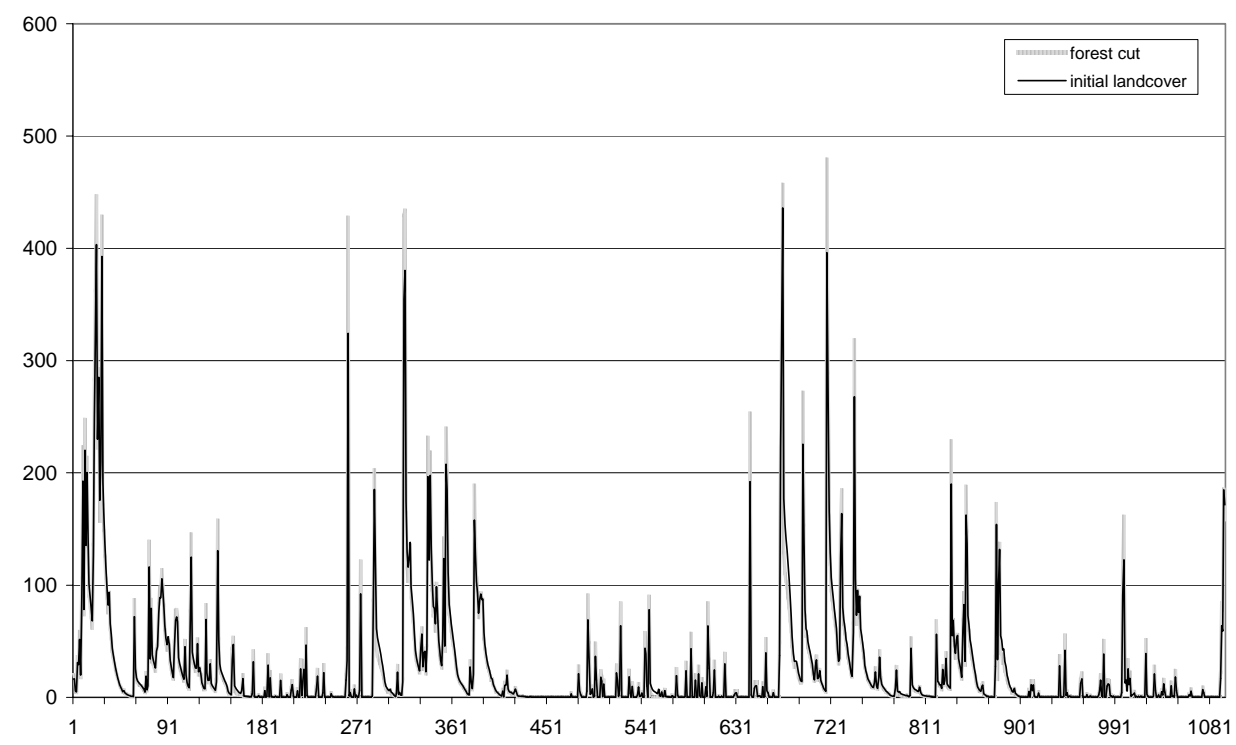

Figure 11. Comparison of the outflows of the river Sapine over 1996-1998 between initial landcover and after blank cutting

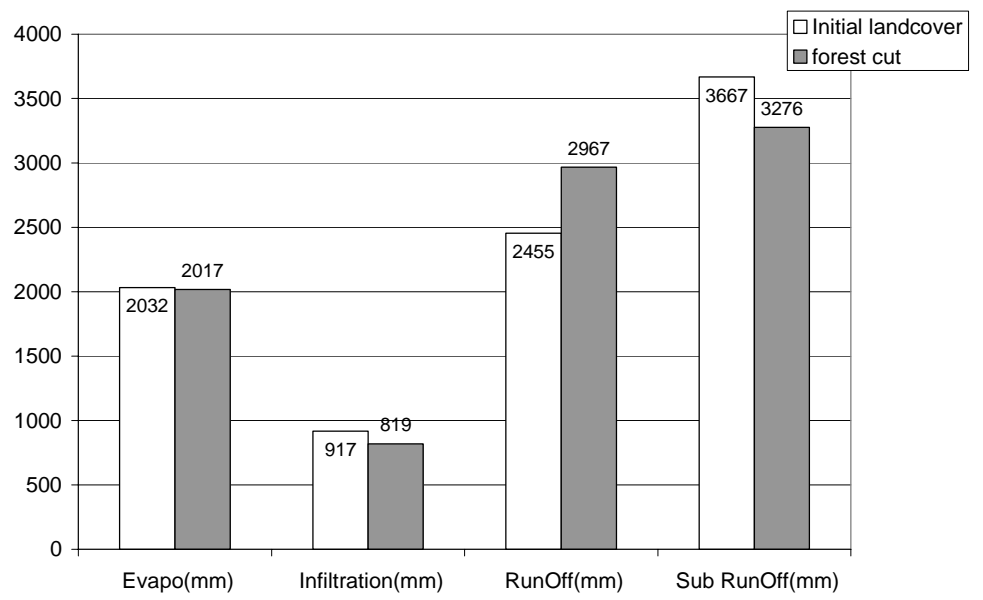

Figure 12. Comparison of basic phenomena involved in water balance evaluation under hypotheses of land use changes (parcels become more impervious)

\section{CONCLUSION}

Earth is subjected to two simultaneous changes: the anthropogenic one and the climatic one. A first task of scientific work is devoted to evaluate the respective part of each factor. A second part is to evaluate the global impact of these changes. The simulation tool we have 
developed takes into account in a separate way these two kinds of changes. We do not deal in this paper about climatic change simulation scenario but it has already been implemented: it consists of real data or virtual ones automatically generated in order to simulate wetter or dryer years in comparison with a mean year. We have focused on the impact of anthropogenic changes. Obtained results show that the simulation well reproduces the general functioning of the brook but the peaks of outflow are not estimated precisely enough. It is then difficult to estimate the impact of the change which would be of the same order of magnitude than the precision of the model. The simulation tool is not yet precise enough to develop detailed analysis. Nevertheless, it is suitable to give orders of magnitude and to be used as a demonstration tool to show general trends and to understand the impact of different parameters on the various items involved in the water balance. Perspectives are to increase the quality of the simulation parameters by a greater lag of time for the measured data and to couple the climatic and anthropogenic scenarios.

\section{REFERENCES}

Anctil F., Rousselle J., Lauzon N., (2005), Hydrologie.Cheminements de l'eau, Presses Internationales Polytechiques, $317 \mathrm{p}$.

Martin C. (2002), Recherche sur le BVRE du Mont-Lozère, Etudes de géographie physique, XXIX , 5-13.

Moges S.A., Katambara Z., Bashar K., (2003), Decision support system for estimation of potential evapo-transpiration in Pangani Basin, Physics and Chemistry of the Earth, 28, 927934.

Nash J.E. and Sutcliffe J.V., (1970), River flow forecasting through conceptual models Part I - A discussion of principles, Journal of Hydrology, 27(3), 282-290.

Ordenovic C., Courbis A.L. and Vayssade B., (2002), Modelling/simulation tool, deliverable 14, european project LOWRGREP (Land-use Optimisation With Regards to Groundwater REsources Protection in the mountain hardrock areas), URL: http://lowrgrep.siteeerie.ema.frl, last access date: May $31^{\text {st }} 2007$.

Ziegler B.P., (1984), Multifacetted modeling and discrete event simulation, Academic Press, San Diego. 